\title{
An Urban community's thoughts about leprosy: a survey in Guyana
}

\author{
ANNE COOK \\ Department of Sociology, Faculty of Social Sciences, The Univer- \\ sity of Guyana, Box 101110, Georgetown, Guyana
}

Received for publication 11 September 1980

\section{Introduction}

The study was prompted by the need to provide a basis for community education work by personnel attached to the Hansen's disease unit of the Georgetown Public Hospital, Guyana. The importance of understanding what attitudes prevail in a community before starting an educational campaign, especially when the subject of the campaign is a disease or condition carrying a stigma, has been proved many times; when dealing with conditions which arouse irrational fears, educators run the risk of increasing rather than reducing anxieties and prejudices if they enter the field ignorant of the community's feelings and beliefs.

A questionnaire survey was considered to be the best method of approach, for although surveys cannot provide the detailed and rich information of indepth interviews, they allow for the coverage of large populations and for the comparison of different population groups, such as age groups - of particular interest in this study. A problem clearly exists in the interpretation of responses to questionnaires, as there may be a wide gap between what people say in response to a questionnaire and their actual behaviour. Reaction to an actual and particular leprosy patient, for example, may be quite different from reaction to 'leprosy patients' in the abstract. However, whilst the questionnaire may be a poor indicator of individual behaviour, it is often an excellent indicator of stereotypical ideas in a community and consequently of how a community will react to, say, the conversion of a leprosarium into a general hospital, or a domiciliary treatment programme, or an educational campaign.

Following Bijleveld ${ }^{1}$ the questionnaire dealt with diseases other than leprosy so that the latter could be viewed in the context of people's thinking about disease in general. As Bijleveld suggests, it is easy to be impressed by the visible horror of advanced leprosy and, we would add, influenced by the long history 
add, influenced by the long history of leprosy in Western thought as a uniquely stigmatizing malady. This should not, however, lead to an assumption that leprosy holds a unique position in the mind of the community one is investigating.

\section{Method}

The area selected for the survey is within Georgetown, the capital. Its population is mixed, with both major ethnic groups and a variety of occupational groups and levels being represented. Response to the survey was good, with few people refusing to be interviewed. In Guyana, as in many Third World countries, there are problems in finding an accurate, up-to-date listing of persons which can serve as a sampling frame, and an alternative method of selection was therefore adopted. The interviewers went to every house in six randomly selected Census Enumeration Districts. They requested the names of all members of each household over the age of 18 , and listed them in the order given by the informant, thereby compiling a sampling frame as they proceeded. Interviews were attempted with every fourth person on the list, the list being built up as the interviewers went along. In this way a quasi-random sample was achieved. The interviewers were university students who had studied social science methodology, and in addition they were given training sessions in the use of the questionnaire. Two hundred and sixty-eight interviews were conducted. There were 15 refusals, and 54 persons could not be contacted. There is what would appear to be a bias in the sample in the direction of an over-representation of females, the distribution being 105 males to 164 females. We have the impression, however, that there actually are more women in the area than men, but this is difficult to substantiate, although the census data for the area do indicate a slight preponderance of females. The ethnic groups were represented thus: Afro-Guyanese 115 (43\%); Indo-Guyanese 108 (40\%); mixed 35 (13\%); other $10(4 \%)$. The occupational groups were represented thus: white collar $61(23 \%)$; skilled manual 33 (12\%); unskilled manual 39 (15\%) and unemployed 135 (50\%). Total 268.

\section{Serious diseases}

We started by finding out what diseases came to the minds of the respondents when asked to give the four they considered most serious. In all, 53 distinct conditions were named, although this number included some vague categories like 'belly pain' and 'joints ache'.

The answers to this and other questions were analysed using age as a variable. The sample was divided into those under 30 and those over. As can be seen from Table 1 leprosy was mentioned spontaneously as a serious disease by $11 \%$ 
Table 1. Seven diseases considered 'most serious'

\begin{tabular}{|c|c|c|c|c|c|c|}
\hline & \multicolumn{2}{|c|}{ Under $30 \mathrm{~s}$} & \multicolumn{2}{|c|}{ Over 30s } & \multicolumn{2}{|c|}{ Total* } \\
\hline & No. & $\%$ & No. & $\%$ & No. & $\%$ \\
\hline Cancer & 61 & 52 & 84 & 56 & 145 & 54 \\
\hline Tuberculosis & 41 & 35 & 63 & 42 & 104 & 39 \\
\hline Venereal disease & 37 & 32 & 42 & 28 & 79 & 29 \\
\hline Typhoid & 30 & 26 & 42 & 23 & 72 & 27 \\
\hline Diabetes & 30 & 26 & 37 & 24 & 67 & 25 \\
\hline Malaria & 22 & 19 & 27 & 18 & 49 & 18 \\
\hline Gastro-enteritis & 21 & 18 & 28 & 18 & 49 & 18 \\
\hline Leprosy & 14 & 12 & 16 & 11 & 30 & 11 \\
\hline
\end{tabular}

*All other diseases were mentioned 35 times or less.

of the respondents as compared with cancer, mentioned by $54 \%$. This, taken in the light of responses to later questions, suggests not that leprosy is considered a mild disease, but rather that it is not a disease which is uppermost in the minds of most people. An additional hypothesis is indicated by the relative infrequency with which two other stigmatizing conditions - madness (13: 5\%) and epilepsy (4: 1\%) are mentioned. Leprosy, madness, and epilepsy are all what might be termed 'biblical' diseases, and whilst it may be only a minority who believe they are afflictions sent by God, this notion has influenced the way in which they are viewed by many more.

The respondents were asked to give reasons for their suggestions. This allows for deductions to be made about what constitutes 'seriousness' in a disease for them. Some of the reasons given are: Cancer: Neither a cure nor the cause can be determined. No cure. It ends up killing you. It's very rarely cured. It eats your inside away. It can only be diagnosed. $T B$ : It's a dangerous disease. There's no cure. It's catching. The victims suffer in a dirty way. You have to be isolated. It's dirty to be coughing and spitting. It results in death. VD: Destroys one's health. Deteriorates one's internal system. It can be contagious. It can kill. It stinks up your inside. You will have to be isolated, leads to blood corruption and children sickness. Loss in private parts. Patient's smell offensive. Causes mental disorder and blindness. Diabetes: Incurable. It's always with you. Serious to life, sucks your blood and eats you away. You have to restrain your diet. It bothers you a long time. You have to use insulin for ever. Typhoid: Small children tend to catch the disease easily. Can kill. Makes people wither up and die. Leaves you bald. It leaves you flighty. It is an epidemic. Malaria: It's caused by using dirty things. Causes pain in the body. Causes lightness of the brain. It's easily caught. Mosquitoes are always present and your chances of getting it are high. It can cause death. Gastro-enteritis: It's very common. Can cause death within hours. It leads to steady vomiting. It kills a lot of children. Children get it very easily. It kills instantaneously. Leprosy: It is infectious and 
has no cure. People scorn you. It's a shameful disease. The only cure comes from the Maker. It leaves you deformed. Because persons have to be isolated. Because there is no cure for it and it eats your flesh and fingernails. It disfigures you. People would not like to have dealings with you.

After the respondents had given their unrestricted views on serious illness, they were asked to choose the four they regarded as most serious from a list of seven presented to them, one of which was leprosy. The other diseases presented (malaria, tuberculosis (TB), diabetes, venereal disease (VD), madness, epilepsy) were offered on the supposition that they would be considered of a seriousness comparable to that of leprosy, and in the case of VD, madness and epilepsy they were, like leprosy, stigmatizing.

Table 2. Frequency of selection as one of four most serious illnesses

\begin{tabular}{|c|c|c|c|c|c|c|}
\hline & \multicolumn{2}{|c|}{ Under 30s } & \multicolumn{2}{|c|}{ Over 30s } & \multicolumn{2}{|c|}{ Total* } \\
\hline & No. & $\%$ & No. & $\%$ & No. & $\%$ \\
\hline Venereal disease & 99 & 84 & 99 & 66 & 198 & 74 \\
\hline Tuberculosis & 85 & 73 & 109 & 72 & 194 & 72 \\
\hline Diabetes & 86 & 73 & 78 & 52 & 164 & 61 \\
\hline Leprosy & 53 & 45 & 88 & 58 & 142 & 53 \\
\hline Madness & 65 & 55 & 71 & 47 & 136 & 51 \\
\hline Epilepsy & 41 & 35 & 48 & 32 & 89 & 33 \\
\hline Malaria & 35 & 30 & 48 & 32 & 83 & 31 \\
\hline
\end{tabular}

*Some respondents selected less than four illnesses.

As can be seen from Table 2, leprosy ranked fourth in the number of selections as one of four 'most serious' diseases. Venereal disease, tuberculosis and diabetes were selected more often, with madness ranking a close fifth. Again the data were analysed by age. Older people were more likely to mention leprosy than younger ones, but the difference was not marked. Venereal disease and diabetes were selected more often by younger respondents. Finally, respondents were asked to name the most serious of the seven listed diseases. Here again VD was most often selected, and whilst leprosy ranked second here, madness and diabetes were selected almost as often. Age differences were not marked, but again, older people were more likely to select leprosy than younger ones (Table 3).

It is clear from these responses that leprosy does not come readily to the minds of many when thinking about illness, but when it has been suggested to them people regard it as a serious and fearful disease. This was especially true for many of the older members of our sample. We proffer an explanation for the consistent age difference similar to that suggested by Bijleveld ${ }^{1}$ who found a corresponding age difference in his African sample: for young Guyanese, leprosy may not be a 'present day' disease which can affect them. Many of the older people's awareness of leprosy may have been heightened by a 
Table 3. Disease selected as 'most serious' from a list of seven

\begin{tabular}{|c|c|c|c|c|c|c|}
\hline & \multicolumn{2}{|c|}{ Under 30 s } & \multicolumn{2}{|c|}{ Over 30s } & \multicolumn{2}{|c|}{ Total } \\
\hline & No. & $\%$ & No. & $\%$ & No. & $\%$ \\
\hline Venereal disease & 39 & 33 & 47 & 31 & 86 & 32 \\
\hline Leprosy & 16 & 14 & 33 & 22 & 51 & 19 \\
\hline Diabetes & 25 & 21 & 19 & 13 & 44 & 16 \\
\hline Madness & 20 & 17 & 23 & 15 & 43 & 16 \\
\hline Tuberculosis & 14 & 11 & 19 & 13 & 32 & 12 \\
\hline Malaria & 2 & 2 & 6 & 4 & 8 & 3 \\
\hline Epilepsy & 2 & 2 & 4 & 2 & 6 & 2 \\
\hline Total & 117 & 100 & 151 & 100 & 268 & 100 \\
\hline
\end{tabular}

youth spent in rural areas where communal ties were close and, leprosy was difficult to conceal and deformity common.

For both age groups the disease most often mentioned as serious was venereal disease. This is, at first sight, a little puzzling since venereal disease is seldom detectable by others from outward appearance and is seldom fatal. To understand why venereal disease figures so prominently, we have first to consider that it has been, and is, a relatively common complaint in Guyana. Next we must look at the reasons given for selecting any of the seven diseases as 'most serious', in order to see what constitutes 'seriousness' for the respondents. In connection with the seven designated diseases, the non-existence of a cure was mentioned most often (by 87 respondents), followed by contagiousness (51 respondents), fatality (36 respondents) and deformity and spoiling of appearance (25 respondents).

As would be expected, these four factors were not applied with equal frequency to all the listed diseases. Diabetes, for example, was overwhelmingly spoken of as a disease with no cure, whilst tuberculosis was most often regarded as serious because of its contagious nature. Venereal disease was also deemed serious most often because of the danger of contagion associated with it. Leprosy was most often thought of as serious because of incurability - by 25 respondents from a total of 51 selecting leprosy. Noticeable in the case of both venereal disease and leprosy, however, was the spread of responses. Those two diseases tap several sources of anxiety and whilst many respondents saw neither of them as fatal, both were considered dirty, shameful, destructive of the body and difficult or impossible to cure.

When we turn to the responses to the question 'Which of these diseases would you be most afraid of getting?' again we find leprosy and venereal disease most often selected. This time, however, they are joined by another stigmatizing condition, madness. Young respondents named madness more often than older ones, with the latter choosing tuberculosis and to a lesser extent leprosy more often than the 'under thirties'. It is difficult to find an explanation for the 
Table 4. Diseases respondents fear

\begin{tabular}{|c|c|c|c|c|c|c|}
\hline & \multicolumn{2}{|c|}{ Under 30s } & \multicolumn{2}{|c|}{ Over 30s } & \multicolumn{2}{|c|}{ Total* } \\
\hline & No. & $\%$ & No. & $\%$ & No. & $\%$ \\
\hline Venereal disease & 33 & 28 & 47 & 31 & 80 & 30 \\
\hline Leprosy & 31 & 27 & 48 & 32 & 79 & 29 \\
\hline Madness & 44 & 38 & 29 & 19 & 73 & 27 \\
\hline Diabetes & 26 & 22 & 27 & 18 & 53 & 20 \\
\hline Tuberculosis & 19 & 7 & 34 & 22 & 53 & 20 \\
\hline Epilepsy & 9 & 8 & 14 & 9 & 23 & 9 \\
\hline Malaria & 6 & 5 & 5 & 3 & 11 & 4 \\
\hline All & 7 & 6 & 15 & 10 & 22 & 8 \\
\hline None & 2 & 1 & 1 & 5 & 3 & 1 \\
\hline
\end{tabular}

*Some respondents mentioned more than one disease.

greater preoccupation of young people with madness, but that older ones should mention tuberculosis more frequently is undoubtedly due to the memories some have of the disease as a common scourge. As with the reasons given for regarding leprosy as serious, a variety of causes for fearing it are named. Cancer is frightening because it kills - leprosy for many reasons.

\section{Curability and fatality}

As will be seen later, venereal disease and leprosy share another similarity; they are both considered by many to be 'shaming'. For many of our respondents, however, these two diseases are quite different in their prognosis.

Only 18 people (7\%) felt that venereal disease was never curable whilst over half (161: 61\%) indicated that leprosy could never be cured. Leprosy is seen as a process of progressive deterioration, especially of the outward appearance, which for most respondents did not resolve itself in death. Conversely, while

Table 5. Perception of the curability of listed diseases

\begin{tabular}{|c|c|c|c|c|c|c|c|c|c|c|}
\hline & \multicolumn{2}{|c|}{$\begin{array}{l}\text { Always } \\
\text { curable }\end{array}$} & \multicolumn{2}{|c|}{$\begin{array}{l}\text { Sometimes } \\
\text { curable }\end{array}$} & \multicolumn{2}{|c|}{$\begin{array}{c}\text { Never } \\
\text { curable }\end{array}$} & \multicolumn{2}{|c|}{ Don't know } & \multicolumn{2}{|c|}{ Total } \\
\hline & No. & $\%$ & No. & $\%$ & No. & $\%$ & No. & $\%$ & No. & $\%$ \\
\hline Tuberculosis & 70 & 26 & 167 & 63 & 25 & 9 & 6 & 2 & 268 & 100 \\
\hline Malaria & 135 & 50 & 117 & 44 & 8 & 3 & 8 & 3 & 268 & 100 \\
\hline Venereal disease & 90 & 34 & 148 & 55 & 18 & 7 & 12 & 4 & 268 & 100 \\
\hline Madness & 35 & 13 & 113 & 42 & 118 & 44 & 2 & 1 & 268 & 100 \\
\hline Diabetes & 31 & 12 & 92 & 34 & 133 & 50 & 12 & 4 & 268 & 100 \\
\hline Epilepsy & 26 & 8 & 106 & 40 & 117 & 44 & 19 & 8 & 268 & 100 \\
\hline Leprosy & 20 & 7 & 71 & 26 & 161 & 60 & 16 & 7 & 268 & 100 \\
\hline
\end{tabular}


venereal disease was thought by most to be usually curable it often led to death after the deterioration of the inner organs.*

The Guyanese, like the Bawanga studied by Bjiveveld, appear to take a pessimistic view of illness. The majority of respondents felt that all of the diseases mentioned, with the exception of leprosy, led to death. It is worth pointing out here that the interviewers were instructed to stress the word 'usually' in asking the question 'Do you think any of these diseases usually kill people?' Leprosy was the disease least often thought of as fatal yet most often deemed incurable. In this respect it resembles madness most closely. So although the questionnaire did not allow for the deeper probing of this issue, it is clear that for our sample madness and leprosy are chronic ailments par excellence, not usually leading to death but condemning the patient to a lifetime of illness.

Table 6. Perception of the fatality of listed diseases

\begin{tabular}{|c|c|c|c|c|c|c|c|c|}
\hline & \multicolumn{2}{|c|}{ Usually kills } & \multicolumn{2}{|c|}{$\begin{array}{l}\text { Does not } \\
\text { usually kill }\end{array}$} & \multicolumn{2}{|c|}{ Don't know } & \multicolumn{2}{|c|}{ Total } \\
\hline & No. & $\%$ & No. & $\%$ & No. & $\%$ & No. & $\%$ \\
\hline Tuberculosis & 195 & 73 & 56 & 21 & 17 & 6 & 268 & 100 \\
\hline Malaria & 171 & 64 & 66 & 25 & 31 & 11 & 268 & 100 \\
\hline Venereal disease & 142 & 53 & 93 & 35 & 33 & 12 & 268 & 100 \\
\hline Madness & 115 & 43 & 122 & 46 & 31 & 11 & 268 & 100 \\
\hline Diabetes & 230 & 86 & 31 & 12 & 7 & 2 & 268 & 100 \\
\hline Epilepsy & 206 & 77 & 46 & 17 & 16 & 6 & 268 & 100 \\
\hline Leprosy & 86 & 32 & 123 & 46 & 59 & 22 & 268 & 100 \\
\hline
\end{tabular}

\section{The recognition of symptoms}

It was considered important to find out what people recognized as symptoms of leprosy, so that officers concerned with public education could have an idea of what imagery of leprosy is prevalent. Few people when asked 'Do you know of any ways to tell if someone has leprosy' gave detailed answers and a substantial proportion (85: 31\%) gave a negative reply. Even fewer (4) discriminated between types of leprosy, those that did using the terms 'wet and dry' leprosy.

Skin abnormalities, excluding sores, were mentioned most often (115:43\%) with 65 people giving no other means of recognition. This is a wide category including several types of skin condition. Some examples of responses placed in this category are: 'The skin gets raw looking. It loses its pigmentation and gets scaly. The skin starts to peel. The skin gets white spots. The skin changes colour. The skin deteriorates. If it's in your blood a rash appears seasonally.' The most common suggestion regarding skin abnormalities was that leprosy can be recognized by the appearance of white spots or a loss of pigmentation.

*It is of interest that several respondents indicated that VD 'leads to' syphilis as it becomes worse. 
Now a whole range of ailments involve skin changes, many of them mild, like allergy rashes, teenage pimples and fungal infections. Grave illnesses that we are frightened of may be all the more threatening when their initial symptoms seem innocuous - a cough, a slight chest pain or whitish patches on the skin - and easily confused with other conditions. Sixty-three respondents (23\%) spoke of deformities usually those involving the hands and, less often, the feet. A typical suggestion was that fingers become 'drawn up' or 'crumped'. Very few (15) referred to a loss of the extremities and even fewer (7) to anaesthesia, or loss of sensation (Table 7).

Table 7. The symptoms of leprosy

\begin{tabular}{|c|c|c|c|c|c|c|}
\hline & \multicolumn{2}{|c|}{ Under 30} & \multicolumn{2}{|c|}{ Over 30} & \multicolumn{2}{|c|}{ Total } \\
\hline & No. & $\%$ & No. & $\%$ & No. & $\%$ \\
\hline Skin & 54 & 46 & 61 & 40 & 115 & 43 \\
\hline Deformity & 25 & 21 & 38 & 25 & 63 & 23 \\
\hline Loss of extremities & 4 & 3 & 11 & 7 & 15 & 6 \\
\hline Sores & 8 & 7 & 6 & 4 & 14 & 5 \\
\hline Flesh nodules & 4 & 3 & 7 & 5 & 11 & 4 \\
\hline Anaesthesia & 2 & 1 & 5 & 3 & 7 & 3 \\
\hline Don't know & 41 & 35 & 44 & 29 & 85 & 31 \\
\hline Other & 6 & 5 & 13 & 9 & 19 & 7 \\
\hline
\end{tabular}

This finding must be interpreted cautiously since Guyanese have comparatively little experience of being interviewed and consequently have not acquired the 'social meaning' of the social research questionnaire. Consequently they often respond to questions of opinion as if they were questions of fact. The interviewers report that respondents, after giving their views on, say, which are the most serious illnesses, would ask if their reply was correct. The apparent ignorance of a significant proportion of our sample about symptoms may in many cases reflect a reluctance to hazard an answer about which they are uncertain in case it is 'incorrect', rather than a complete absence of ideas on the subject.

\section{Shame, scorn and disease}

When asked to name those diseases of the seven that were considered 'shaming', respondents of both age groups overwhelmingly specified venereal disease and leprosy. Seventy-two per cent said that they would not let others know if they had leprosy. An examination of the reasons given for a disease being shaming suggests that responses fall into three basic categories: a disease is shaming because of its cause, the discreditable symptoms it has, and the reaction of others to those who have it. The shame associated with venereal disease is because of its sexual associations. Guyanese are not puritanical in their approach 
to sexuality and yet there is a reticence about its public display and discussion. A person publicly known to be a venereal disease sufferer offends this reticence.

The shame associated with leprosy and venereal disease contributes to a reluctance to seek treatment with qualified doctors or at public clinics. People with VD may attempt treatment themselves or with 'traditional' healers rather than risk being seen to enter a social disease clinic. Concealment of leprosy or venereal disease obviously poses a threat to the early diagnosis and treatment of these diseases in Guyana.

Educational programmes alone tend to have limited success in changing entrenched attitudes. Attempts to persuade the public that a disease is not shameful when people are quite convinced that it is, simply do not work. This attitude may be strengthened in some countries by poor facilities for the treatment of venereal disease, leprosy and insanity, together with punitive legislation against those afflicted.

In Guyana, the bright new clinic for the treatment of skin disorders will probably have more effect than mere words in convincing people that leprosy should be regarded as an illness requiring prompt treatment like any other, rather than a curse which leads inevitably to shameful degeneration and isolation from society.

\section{Willingness to associate}

Respondents were asked to indicate their willingness or otherwise to associate with a person being treated for leprosy or allow their children to associate, at different levels of intimacy - in a working relationship, a friendship relationship, having a child visit a patient, having a child marry a patient.*

Over half the sample said that they would be willing to work with, or befriend a patient. This figure must be interpreted cautiously for friendliness and tolerance are important social values for Guyanese, and the reaction of

Table 8. Willingness to associate

\begin{tabular}{|c|c|c|c|c|c|c|c|c|}
\hline & \multicolumn{2}{|c|}{ Yes } & \multicolumn{2}{|c|}{ No } & \multicolumn{2}{|c|}{ Don't know } & \multicolumn{2}{|c|}{ Total } \\
\hline & No. & $\%$ & No. & $\%$ & No. & $\%$ & No. & $\%$ \\
\hline Would work at same place & 145 & 54 & 109 & 41 & 14 & 5 & 268 & 100 \\
\hline Would be friends with & 156 & 58 & 98 & 37 & 14 & 5 & 268 & 100 \\
\hline Would allow child to visit & 113 & 42 & 128 & 48 & 27 & 10 & 268 & 100 \\
\hline Would allow child to marry & 16 & 6 & 215 & 80 & 37 & 14 & 268 & 100 \\
\hline
\end{tabular}

*The questions were centred on the phrase 'a person being treated for leprosy' rather than 'a person with leprosy' or even 'a leprosy patient' as the intention was to test people's reaction to persons who are non-infectious, thus isolating stigma from fears of infection. This intention was not fulfilled however, as so few people are apparently aware that treatment renders a patient non-infectious. 
many to the hypothetical situations put to them may well have been tempered by a desire to give a 'socially acceptable' response. Those who work with leprosy patients can give many examples of the norms attached to these social values breaking down, with the result that patients are repudiated as friends and rejected as fellow-workers. Fewer respondents reacted positively to the idea of having their children mix with patients. The most outstanding finding within this area was that a mere 16 respondents claimed a willingness to allow a son or daughter to marry a patient. Now there were indications that the notion that leprosy is hereditary is not urcommon, but that alone cannot account for this almost unanimous rejection of patients as children's marriage partners. If we remember that leprosy is thought of as a hopeless disease, with no cure and no release through death, it becomes reasonable to feel that patients make poor marriage prospects. Furthermore a family relationship which threatens to taint one with the patient's stigma may be intolerable.

\section{The treatment of leprosy}

Our respondents were asked where leprosy should be treated, and were offered a choice of Mahaica Hospital, any other hospital, or domiciliary treatment. The majority (209: 78\%) felt that Mahaica Hospital was the place for treatment, although a few of this number (9) saw domiciliary treatment as an alternative (Table 9). In Guyana leprosy is now treated on a domiciliary basis. The specialist hospital at Mahaica houses 'old' patients and is rarely used for new admissions. ${ }^{2}$

Table 9. Choice of treatment

\begin{tabular}{lrr}
\hline & No. & $\%$ \\
\hline Mahaica Hospital & 200 & 75 \\
Mahaica Hospital or domiciliary & 9 & 3 \\
Any hospital & 21 & 8 \\
Domiciliary & 33 & 12 \\
Don't know & 5 & 2 \\
\cline { 2 - 3 } Total & 268 & 100 \\
\hline
\end{tabular}

The responses suggest that the overwhelming selection of Mahaica probably came about for several reasons. Some people feel that Mahaica is best for the patient as it offers specialist care. Others no doubt made the same choice feeling that the confinement of patients offers society protection from contagion and also from the anxiety and embarrassment which is aroused by social contact with the 'abnormal'. In this connection, it is of interest that $178(66 \%)$ agreed with the statement that 'Leprosy patients should be kept away from other people' even though only 90 (34\%) felt that 'It is dangerous to touch a leprosy patient.', which seems to suggest that fear of contagion is not the only, nor even perhaps the main reason for the rejection of leprosy patients. 
Respondents had few suggestions to offer regarding the treatment and cure of leprosy. Most (181:67\%) said they didn't know how this could be accomplished, to which number must be added a further 52 respondents (19\%) who mentioned a place of treatment - Mahaica, a clinic, 'at the doctor's' - rather than a method. Of this 52 many stated that leprosy could be treated but not cured, which perhaps explains the recurrence of the phrase 'only at Mahaica' in these answers, the implications being that the specialist hospital is the only place where anything much can be done, and this falling short of actual cure. Seven people spoke vaguely of injections, drugs, or medicine, four of prayer, two of the efficacy of 'bush' - herbal remedies - and one that of marijuana. Only two mentioned a specific treatment; one dapsone, the other sulphur. The area of treatment seems to be where educational programmes could focus most effectively. If people can be assured that leprosy can be treated and contained then this should reduce the fatalism with which it is viewed, and this in turn improve attitudes towards patients and decrease the incidence of 'hiding' and defaulting on treatment.

\section{The prevention of leprosy}

There was a greater abundance of ideas as to how leprosy could be prevented. The preventive measure most often recommended was to simply keep away from people with the disease. Others mentioned cleanliness, the avoidance of certain foods, making regular checks with a doctor and the use of marijuana. Most (163: 61\%) could make no suggestions.

It is notable, however, that $49(18 \%)$ respondents agreed with the statement 'Some foods give you leprosy.', and a further 123 (46\%) showed uncertainty, stating that they did not know if this was so. Also $48(18 \%)$ agreed that leprosy could be contracted if obeah (supernatural arts) were used against one, although $161(60 \%)$ disagreed, with 59 (22\%) being uncertain.

It can be concluded then, that folk ideas about the prevention and cure of leprosy persist in this urban community. Only two respondents recommended folk methods of treatment for leprosy, however, and it seems accepted that the appropriate treatment of leprosy is offered by qualified doctors.

\section{Conclusions}

Leprosy is regarded as a serious and fearful disease by urban Guyanese. This does not appear to be a function only of the characteristics of the disease but results from a perception of leprosy as stigmatizing. A vicious circle is thereby created: people 'scorn' leprosy because of the stigma attached and the stigma is attached to leprosy because people 'scorn' it. Thus leprosy belongs to that group of diseases that 'discredit' their victims. What makes leprosy particularly 
frightening, especially for older people, is the prevalent notion that it is incurable, yet not fatal. At this point we would mention the fact that during the course of the interviews not a single respondent indicated a knowledge of the fact that treatment renders a patient non-infectious. The treatability of leprosy is the point which can be stressed most profitably in education programmes. It seems reasonable to expect that once the view of leprosy as untreatable is corrected, then fears about contagion may be more easily allayed, domiciliary treatment may be more acceptable, and gradually the stigma may begin to fade. This would seem to be the area where education is most needed and where there is most chance of effecting a break in the 'vicious circle' of stigma.

Younger people, as a group, seem less aware of, and less af raid of, leprosy. Perhaps health programmes addressed to them in schools and universities can capitalize on this and emphasize the treatment of leprosy along with that of other diseases.

\section{Acknowledgement}

The survey was generously funded by the American Leprosy Missions, Inc.

\section{References}

1 Bijleveld I. Leprosy and other diseases in the three wangas: community thought patterns about health care and their consequence for emergent patients. Royal Tropical Institute, Amsterdam, 1976.

2 McDougall A C, Rose P. Integrated leprosy control in Guyana. Bull Pan Am Hlth Org $1978 ; 12: 11-6$. 